\title{
Appraisal of prescription writing skills of preclinical undergraduate students in a medical institute of Nepal
}

\author{
J. Kumar ${ }^{1}$, M. M. Shaik ${ }^{2}$, M. C. Kathi ${ }^{3}$, M. S. Chetty ${ }^{4}$, A. Deka ${ }^{5}$ \\ ${ }^{1}$ Associate Professor, ${ }^{2}$ Assistant Professor, ${ }^{3}$ Lecturer, ${ }^{4}$ Professor, ${ }^{5}$ Prof. and Head, Department of Pharmacology, College of \\ Medical Sciences, Bharatpur, Nepal
}

\begin{abstract}
The aim of this study was to appraise the prescription writing skills of preclinical undergraduate students of College of Medical Sciences, Bharatpur. This prospective study was conducted over each of 150 of $1^{\text {st }}$ year and $2^{\text {nd }}$ year medical students in the months of May and June 2010 under the guidelines of World Health Organization (WHO). Prescriber's identity, patient's identity, the diagnosis, the symbol-Rx and prescriber's signature were available on $90 \%$ and above of the prescriptions written by both year students. A large number of them also mentioned the prescriber's address and the date of prescription. The information, instructions, warnings and patient's address were the most deficient aspects among prescriber's related components and the strength, the quantity to be dispensed and the direction for the use of drugs were the deficient aspects of drug related components. Comparatively more deficiencies were noted for drug related components. As an overall, the performance of $2^{\text {nd }}$ year medical students was better than that of the $1^{\text {st }}$ year. This study reveals that the prescription writing skills of preclinical medical students were sub-optimal and need emphasis for some elements during their clinical years and internship. However, there is a good scope of learning this skill also in the existing method of pharmacology teaching.
\end{abstract}

Key words: Prescription writing, medical students, pharmacology teaching.

\section{Introduction}

The prescription is the most common clinical intervention offered to the patients. Almost all interaction between a doctor and a patient ends with writing of a prescription. The prescription writing is a clinical skill that determines largely the outcome of a therapeutic decision. The suboptimal prescription writing skill can lead not only to therapeutic failure but also to wastage of our resources, adverse clinical consequences and economical harm to both patients and the

Correspondence: J. Kumar

E.Mail: drjktkhag2003@yahoo.co.in community. The ability to prescribe commonly used drugs safely and effectively is a core competency expected from all medical graduates. ${ }^{1}$ They learn this skill under the discipline of pharmacology. This discipline is taught in most of the Kathmandu University (KU) affiliated medical colleges in an integrated manner with other basic medical science subjects during the first two years of the undergraduate medical course following the traditional teaching methods. However, the revised curriculum of $\mathrm{KU}$ gives much emphasis on the training of medical students for rational prescribing using the World Health Organization (WHO) 
guidelines to good prescribing as the reference standard. ${ }^{2,}{ }^{3}$ The College of Medical Sciences (COMS) Bharatpur is affiliated to KU. Therefore students of this medical college are taught about the standard pharmacotherapeutic approach to common clinical disorders including the procedures of P- drug selection and Essential drugs concept. There is a growing concern that the traditional undergraduate teaching in pharmacology does not train the medical students adequately for therapeutics. ${ }^{4,5}$ The prescription writing skills of medical students have been reported to be suboptimal even in the settings of problem based pharmacology teaching. ${ }^{7}$ The prescription writing skill of preclinical medical students was reported suboptimal also in a recent study conducted in the eastern Nepal. ${ }^{8} \mathrm{~A}$ regular assessment of medical students on their prescription writing skills during their training has been suggested as a means of minimizing the related errors and enhancing rational prescribing in their future endeavors. ${ }^{9}$ There is no any published data on this skill of preclinical undergraduate students of COMS Bharatpur. Therefore the present study was planned and undertaken with an objective to assess the prescription writing skills of preclinical undergraduate medical students of this medical institute of Nepal. This study has been attempted also with an intention to assess the effectiveness of the existing method of pharmacology teaching in context of rational therapeutics so as to suggest any addition or a change in them.

\section{Material and methods}

This prospective study was carried out in the department of pharmacology on preclinical medical students of COMS Bharatpur in the months of May and June 2010 during their pre-university examination. 150 students of 1 st year and 150 students of 2nd year MBBS course constituted the whole study population. The prescription writing skills of these students were assessed along with other aspects of their practical examination as a part of summative assessment through a pharmacotherapy objectively structured practical examination (OSPE) following the guidelines recommended by WHO. ${ }^{10} \mathrm{~A}$ number of OSPE stations were made to maintain the objectivity in the questions as well as to maintain the uniformity in the making of responses by students. The questions for OSPE stations were framed keeping in mind the objectives of the concerned exercises and specific answer checklists were made for all the questions after a detailed discussion with faculty members of the department. Among all the OSPE stations, at least one station included the prescription writing exercise for a common clinical condition. Students of both years were priorly explained the nature of this study. They were given a common clinical condition by lottery method to write a prescription. Students of different years were given different sets of common conditions depending on the part of pharmacotherapy covered in their respective year of teaching. They were assessed thereafter for their performance using preformed checklists for both the two important divisions of a prescription i.e. the physician related components and the drug related components. The physician related components were comprised of prescriber's identity, professional degree and registration no., prescriber's address, date of prescription, patient's identity, patient's address, the symbol Rx, diagnosis, information, instructions and 
J. Kumar et al, Appraisal of prescription writing skills of preclinical

warnings to patient, and prescriber's signature. The drug related components were appropriateness of $\operatorname{drug}(\mathrm{s})$ selected, strength of drug(s), dosage forms, direction for use of drugs and quantity to be dispensed. Subsequently, the score lists for different elements of two components of written prescriptions by two individual year students were prepared. The mean score rates for different components of prescriptions written by different years of students were also calculated. The anonymity of identity of all the respondent students was maintained in this study. The number and the percentage were used to express the observed data. The data obtained were statistically analyzed using chi-square test. P-values $<0.05$ and $<0.01$ were considered statistically significant and highly significant respectively.

\section{Results}

A total of 300 prescriptions written by the same number of preclinical medical students were analyzed to evaluate their skill in the concerned area. The performance score for the physician related components of first year students ranged from lowest $61.33 \%$ to highest $98 \%$, whereas that of second year students ranged from lowest $84.66 \%$ to highest $100 \%$ for various elements. The percentage of prescriptions containing the prescriber's identity, patient's identity, diagnosis, the symbol Rx and the prescriber's signature was $90 \%$ and above in both years students. The performance score for the prescriber's address was $97.33 \%$ i.e. above $90 \%$ among second year students, whereas that was $89.33 \%$ i.e. below $90 \%$ among first year students. Among the first year students, the most deficient part of physician related components were the information and the instructions followed by the patient's address as these were written only by $61.33 \%$ and $64.66 \%$ of the students respectively. Surprisingly these two elements also constituted the most deficient aspect of physician related components among the second year students. However, the second year students performed better than the first year students in this respect, as these two elements were written properly by $87.33 \%$ and $84.66 \%$ of them respectively. Moreover the differences observed in the performance for these elements in between first and second year students were found to be statistically highly significant and significant respectively. The next deficient element among physician related components of first year students was professional degree and registration number as it was marked only by $67.33 \%$ of them. However, this particular element of prescription was written by a comparatively better number of second year students i.e. $90 \%$ and the difference in the number of respondents observed in between two different years of students was found to be once again statistically significant.

Among the drug's related components, the performance score ranged from lowest $44.66 \%$ to highest $85.33 \%$ among the first year students and the lowest $67.33 \%$ to highest $88.66 \%$ among the second year students. The drug(s) selected for the given condition were found to be appropriate on $85.33 \%$ and $88.66 \%$ of prescriptions written by the first year and second year students respectively. Both year students performed comparatively better for this element among the drug related components. The most deficient aspects of this component were found to be the strength of drug(s), the direction for use and quantity to be dispensed in both years of students. However, the second year 
Journal of College of Medical Sciences-Nepal,2010,Vol-6,No-4

students performed better than the first year students for these elements and the observed differences for strength and quantity to be dispensed are statistically significant and that for direction for use is highly significant. Further details of performance of both year students in their prescription writing skill have been produced in Table-1.

Table 1: Performance in prescription writing skill of first and second year medical students

\begin{tabular}{|c|c|c|c|c|c|}
\hline \multirow{3}{*}{$\begin{array}{c}\text { S. } \\
\text { No. }\end{array}$} & \multirow{3}{*}{ Prescriber related components } & \multicolumn{2}{|c|}{ Components } & \multicolumn{2}{|c|}{ Medical Students } \\
\hline & & \multicolumn{2}{|c|}{ First Year $(\mathbf{n}=150)$} & \multicolumn{2}{|c|}{ Second Year $(n=150)$} \\
\hline & & Number & Percentage & Number & Percentage \\
\hline 1. & Prescriber's identity & 147 & 98.00 & 148 & 98.66 \\
\hline 2. & Professional Degree and registration no. & 101 & 67.33 & 135 & $90.00 *$ \\
\hline 3. & Prescriber's address & 134 & 89.33 & 146 & 97.33 \\
\hline 4. & Date of prescription & 130 & 86.66 & 134 & 89.33 \\
\hline 5. & Patient's identity & 146 & 97.33 & 147 & 98.00 \\
\hline 6. & Patient's address & 97 & 64.66 & 127 & $84.66^{*}$ \\
\hline 7. & Diagnosis & 147 & 98.00 & 150 & 100.00 \\
\hline 8. & Symbol-Rx & 135 & 90.00 & 144 & 96.00 \\
\hline 9. & Prescriber's signature & 137 & 91.33 & 142 & 94.66 \\
\hline 10. & Information, instructions and warnings & & & & \\
\hline & to patient & 92 & 61.33 & 131 & $87.33 * *$ \\
\hline & Drug related components & & & & \\
\hline 1. & Appropriateness of drug selected & 128 & 85.33 & 133 & 88.66 \\
\hline 2. & Strength of drug & 77 & 51.33 & 107 & $71.33^{*}$ \\
\hline 3. & Dosage form & 105 & 70.00 & 118 & 78.66 \\
\hline 4. & Quantity to be dispensed & 70 & 46.66 & 101 & $67.33^{*}$ \\
\hline 5. & Direction for use & 67 & 44.66 & 101 & $67.33 * *$ \\
\hline
\end{tabular}


J. Kumar et al, Appraisal of prescription writing skills of preclinical

The mean scores observed for the physician related components and drug related components of the first year students were $84.4 \%$ and $59.6 \%$ respectively and that for second year students were found to be comparatively better i.e. $93.6 \%$ and $74.6 \%$ respectively. It is evident from the result that both year students scored less in the drug related components of their prescriptions in comparison to their physician related components (Table-2). The results also suggest that the overall performance of second year students was better than the first year students for all the elements of both the physician related and the drug related components.

Table 2: Comparison of mean scores of different components of prescription between two different years of medical students

\begin{tabular}{lccc}
\hline Category & $\begin{array}{r}\text { So. of } \\
\text { students }\end{array}$ & $\begin{array}{c}\text { Physician related } \\
\text { components (\%) }\end{array}$ & $\begin{array}{c}\text { Drug related } \\
\text { components (\%) }\end{array}$ \\
\hline First year medical students & 150 & 84.4 & 59.6 \\
Second year medical students & 150 & 93.6 & 74.6 \\
\hline
\end{tabular}

\section{Discussion}

An ideal prescription paper should include all its important elements to ensure a well communication in between a prescriber and a pharmacist. The omission of any of the needed information on a prescription paper could result in miscommunication and medication errors. ${ }^{3}$

The performance scores of students of both year for majority of elements of both the prescriber related components and the drug related components were observed to be only below hundred percent in our study. This observation suggests that the acquisition of prescription writing skill among preclinical students of our institute is deficient at least to some extent. This observation is in accordance with that observed in the study of eastern Nepal. ${ }^{8}$ Al Khaja et al from Bahrain also reported the limited acquisition of prescription writing skill of medical students during their preclerkship period. ${ }^{7}$ In a Nigerian study, final year

medical students were found to be also deficient in their prescription writing skills. ${ }^{9}$ However, important elements of a prescription like the prescriber's and patient's identity, the diagnosis, the symbol-Rx and the prescriber's signature were available on the prescriptions of majority (>90\%) of both year students in our study. The prescriber's address and the date of prescription were also available on the prescriptions of a large percentage (>85\%) of both year students in our study. The prescriber's identity and address on the prescription are essential to ensure a timely approach by the pharmacist to the physician for a clarification in case of any confusion. ${ }^{11}$ Patient's identity and address are equally important to ensure that the correct medication goes to the correct patient and also for the purpose of identification and recordkeeping. ${ }^{12}$ Presence of these elements also provides an opportunity to the pharmacist to contact the 
concerned patient timely in case of occurrence of any prescribing or dispensing error. ${ }^{9}$ The date of prescription is an important part of the patient's medical record that also assists the pharmacist to recognize the potential problems including noncompliance. ${ }^{12}$ Majority (>85\%) of both year students were also able to choose the right drug for the given condition. This proves their understanding of pharmacotherapeutic approach for the common clinical conditions. Taking into account all of these favorable findings of our study, it can be concluded that in spite of a limitation there is a good scope for acquisition of this skill even in the settings of traditional pharmacology teaching particularly when combined with emphasis on the teaching and exercising of the steps of rational prescribing set forth by WHO. ${ }^{3}$

Among the prescriber related components, the information, instructions and warnings and patient's address were the deficient aspects in both years. However, the performance of second year students was significantly better for these elements. The relevant information, instructions and warnings are needed not only to ensure compliance and subsequent success of given therapy but also to prevent any adverse event related to therapy. These elements need to be emphasized in the forthcoming teaching sessions.

The drug related components of prescriptions of both year students were observed to be deficient regarding strength, dosage forms, quantity to be dispensed and direction for use of drugs. The inadequate attention paid for these arenas by the students might be the reason for such deficiencies. Therefore these arenas need to be focused and emphasized well by the concerned teaching faculties in the future to prevent such shortcomings. A continuous effort to improve these parts by students in their coming academic years can also help to overcome these deficiencies. This is better explained by the observation that the second year students performed significantly better than the first year students in our study for the strength, quantity to be dispensed and direction for use of drugs. The overall performance of both year students for the drug related components in our study were more deficient in comparison to the prescriber related components. This observation is in conformity with that observed in the study of Bahrain. ${ }^{7}$ It can be concluded from these observations that the drug related components of a prescription are comparatively a difficult part and need special attention of teachers as well as students.

This study also demonstrates that the overall performance of second year students is better than the first year. This is suggested by our finding that the mean scores of second year students for the physician related components and drug related components were $93.6 \%$ and $74.6 \%$ respectively, whereas that of first year students were only $84.4 \%$ and $59.6 \%$ respectively. Comparatively, more prolonged opportunity and exposure, almost evenly spread over two years to build up the prescription writing skill seems to be the underlying reason behind the better performance of second year medical students. The better performance of second year students in comparison to first year students also suggests that the learning of prescription writing skill is a gradual process that builds up by the practice over years. Therefore this requires an extended effort and exposure even in their clinical years and internship to gain the perfectness. 
J. Kumar et al, Appraisal of prescription writing skills of preclinical

\section{Conclusion}

This study reveals that the acquisition of prescription writing skill of medical students during their preclinical years is only suboptimal. There is an urgent need to pay more attention during preclinical years for most of the drug related components and few but important elements of the prescriber related components. Though there is a limited but fairly good scope for learning of this skill by the preclinical students even in the settings of traditional teaching of pharmacology, particularly when emphasis has been laid down on the steps suggested by the WHO for rational prescribing. However, more investigations are required to confirm this conclusion. The acquisition of expected competency in this skill also requires an extended effort by the medical students as well as the teachers in the clinical years and internship period. Frequent formative assessment of students for this skill at regular intervals is recommended during preclinical as well as clinical years to point out the defects and to provide feedbacks to students so as to minimize the related errors in them.

\section{References}

1. A. Heaton, D.J.Webb, S.R.J. Maxwell. Undergraduate preparation for prescribing: the views of $2413 \mathrm{UK}$ medical students and recent graduates. $\mathrm{Br} J$ Clin Pharmacol 2008; 66(1): 128-34.

2. Kathmandu University. Curriculum for bachelor of medicine and bachelor of surgery (MBBS) part-one Basic medical sciences; Edited $3^{\text {rd }}$ version. Dhulikhel. Kathmandu University, 2007.

3. T.P.G.M.deVries, R.H. Henning, H.V. Hogerzeil, et al. Guide to good prescribing: a practical manual. Geneva: World Health Organization; 1994. WHO/DAP/94.11.
4. M.P. Joshi. Problem-oriented pharmacotherapy teaching: essentials of medical education. Kathmandu: Health Learning Materials Centre; 1996.

5. M.C. Michel, A. Bischoff, M.Z. Heringdorf, et al. Problem vs. lecture-based pharmacology teaching in a German medical school. Naunyn-Schmiedeberg's Arch Pharmacol 2002; 366: 64-8.

6. P.R. Shankar, N. Jha, O. Bajracharya, et al. Teaching pharmacology at a Nepalese medical school: the student perspective. Australasian Medical Journal 2010; 1: 14-22.

7. K.A.J.Al Khaja, S.S. Handu, H. James, et al. Assessing prescription writing skills of preclerkship medical students in a problem-based curriculum. Int J Clin Pharmacol Ther 2005; 43(9): 429-35.

8. G.P. Rauniar, R.K. Roy, B.P. Das, et al. Prescription writing skills of pre-clinical medical and dental undergraduate students. J Nepal Med Assoc 2008; 47(172): 197-200.

9. K.A. Oshikoya, J.A. Bello, E.O. Ayorinde. Prescribing knowledge and skills of final year medical students in Nigeria. Ind J Pharmacol 2008; 40(6): 251-5.

10. Y.E. Kocabasoglu. How to assess the students. In: H.V. Hogerzeil, K.I. Barnes, R.H. Henning, et al. Teacher's guide to good prescribing. Geneva: World Health Organization; 2001: 51-66.

11. P.W. Lofholm, B.G. Katzung. Rational prescribing and prescription writing. In: B.G. Katzung editor. Basic and clinical pharmacology. $9^{\text {th }}$ edi. NewYork : McGraw-Hill; 2004:1091-100.

12. I.L.O. Buxton. Principles of prescription order writing and patient compliance. In: L.L. Brunton, J.S. Lazo, K.L. Parker, editors. Goodman \& Gilman's the pharmacological basis of therapeutics. $11^{\text {th }}$ edi. NewYork: McGraw-Hill; 2006: 1777-86. 